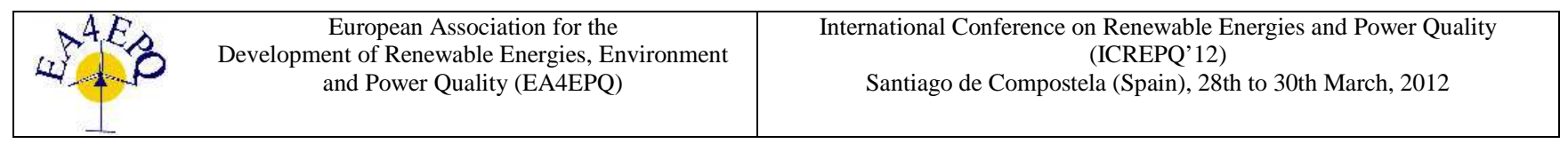

\title{
Stochastic modelling of EV charging at charging stations
}

\author{
Csaba Farkas ${ }^{1}$, László Prikler $^{1}$ \\ ${ }^{1}$ Department of Electric Power Engineering \\ Budapest University of Technology and Economics \\ Egry József street 18., Budapest, H-1111, Hungary \\ Phone/Fax number: +3614633015 , e-mail: mooncladreflection@gmail.com, prikler.laszlo@vet.bme.hu
}

\begin{abstract}
It is reasonable to suppose that not every electric car will be charged at home sockets: some vehicle owners will eventually use charging stations. There are two options for such a charging station: it can be built either at the parking lots of shopping centers, or along highways, similar to the gas stations of today. These charging stations of course require additional feed-in of electric energy. To calculate the necessary capacity of such infeed one has to know the main operating parameters of the charging stations, such as the number of charging sockets or the parking capacity of the station. Another important parameter is the time needed to charge the battery. People do not like waiting, so a charging station must be designed taking these constraints into consideration.

In this article the mathematical model of charging stations is proposed, followed by the results of the numerical simulations based on stochastic modelling of EV charging.
\end{abstract}

\section{Key words}

Stochastic modelling, EV charging station, Markov chain, Poisson process

\section{Introduction}

We can expect a second renaissance of electric vehicles $(\mathrm{EV})$ in the near future: oil prices are high and there are several EU directives that aim to develop and create an intelligent and sustainable transportation in the near future. Electric cars fit perfectly into this scope.

Electric cars must be recharged, just as the cars with internal combustion engines must be refuelled. An adequate way of recharging a car is charging it at home or at the street where the car is parked. But these are not the only options for this process: when going for a trip at weekends or when travelling far, alternatives of the gas stations are needed. These are the charging stations, placed by motorways and highways, where vehicle owners can recharge their cars' batteries and have a rest meanwhile.

Another place where a great number of charging sockets could be concentrated is the parking lots of supermarkets. People usually spend more than an hour doing their shopping and it is reasonable to suppose that meanwhile they would want to have their cars charged.

Of course these stations and parking lots have limited capacity, so when designing such a station one must take every constraint into consideration: the amount of expected electric power, the number of charging sockets, the area of the parking lot, etc.

To tell when a single car will come to a charging station is nearly impossible, but when investigating a large number of cars we can make predictions based on probability theory and so have an idea about the parameters needed to construct such a station.

\section{Basics of queueing theory}

Queueing is an unpleasant event we have to face every day: we queue in the shop, at the bank, etc. But not only us, human beings queue: processes at an internet server, phone call requests, etc. also have to wait, hence queue. And what we intend to investigate here: electric cars arriving to a charging station might as well have to wait.

The theory of queues have their own mathematical representation: queueing theory. Queueing theory is a part of dynamic system theory and can be divided into two main parts: deterministic and stochastic processes [1].

- The first class of dynamic processes are the deterministic processes. We have a certain knowledge about the process, we know when the process is to be served and the capacity it requires.

- The second class of dynamic processes are the stochastic processes. We do not have information about the times when the request to serve a process arrives, nor do we have information about the capacity it requires to serve such a request. Most of the processes that occur in real life are from this class.

We can further divide the class of stochastic processes into sub-classes:

- stationary processes

- Markov processes

- $\quad$ birth-death processes

- semi-Markov processes

- Poisson processes

- etc.

Mathematically we can use a birth-death process when we would like to model a queue. During a birth-death process a new element is "born" (in other words a request 
appears in the system) in a population of $i$ members with the probability of $\lambda_{i} \cdot t$ within a short $t$ time interval and an existing element "dies" (or a request is served) with the probability of $\mu_{i} \cdot t$. The birth-death process is in fact a Markov-chain that describes the evolution of a certain population [2]. A Markov-chain can be described as a random walk on an $S$ state-space. If there is a step to the $i^{\text {th }}$ state, then it will stay there for a random time interval. The duration of this time interval however follows an exponential distribution with a parameter $\lambda(i)$. After this it transitions from the $i^{\text {th }}$ state to the $j^{\text {th }}$ state. The probability of this transition is $Q_{i j}$, where $Q$ is the transition probability matrix. The exact definition is the following [3]:

Definition: The $X(t), t \geq 0$ stochastic process on the $S$ state-space is a continuous time Markov-chain if for every $n$ and $s, t>0, t_{0}<t_{1}<\ldots t_{n-1}<t$ and $i, j, i_{0}, i_{1}, \ldots, i_{n-1} \in S$ states the following equation is true:

$$
\begin{aligned}
& P\left(X(t+s)=j \mid X(t)=i, X\left(t_{n-1}\right)=i_{n-1}, \ldots,\right. \\
& \left.X\left(t_{1}\right)=i_{1}, X\left(t_{0}\right)=i_{0}\right)=P(X(t+s)=j \mid X(t)=i) .
\end{aligned}
$$

This equation means - just as with discrete time Markovchains - that if we know the present $X(t)=i$ state of the process, the future $X(t+s)=j$ state is independent from the $X\left(t_{n-1}\right)=i_{n-1}, \ldots, X\left(t_{1}\right)=i_{1}, X\left(t_{0}\right)=i_{0}$ past of the process.

Considering EVs, the state space can be partitioned as follows:

- a car arrives to charge

- a car is charged, so the request is served

It can easily happen that an incoming request (eg. a car arriving to charge its battery) cannot be served because all servers (charging slots) are busy. This means that the request - in our case the $\mathrm{EV}$ - has to wait. We present a method to calculate the parameters that are required to design a charging station where cars do not have to wait.

In the next section we are going to investigate continuous time Markov-chains, because the whole charging process can be modelled as a Poisson process. A Poisson process is the series of births in a pure birth process with constant $\lambda$ parameter. Under such conditions we can consider the Poisson process as arrival of requests in a system [1], [5]. It can be mathematically proved [1], [5] that the

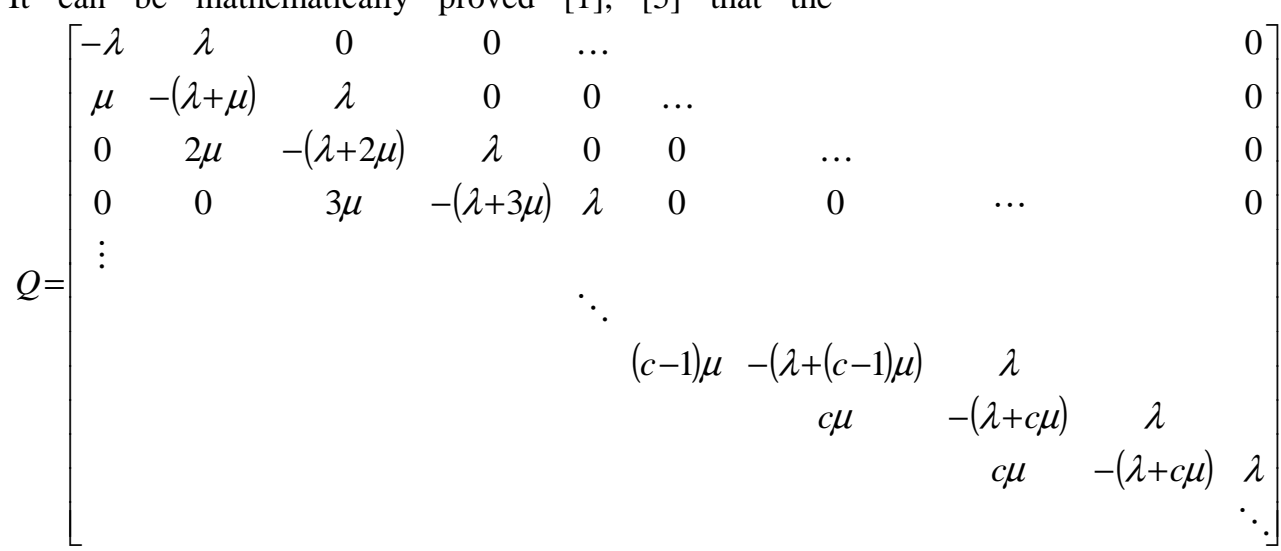

distribution of arrival times are exponential and independent from each other.

A Poisson process is a good approximation of processes where the following are true:

- the number of entities is great

- a single entity does not effect the system significantly

- $\quad$ entities are independent from each other

An electric vehicle's power demand is relatively small compared to the loading of the distribution grid, the arrival time of each car and so the beginning of the charging is independent from the others: these mean that EV charging can be modelled as a Poisson process [6].

\section{Modelling of EV charging at a charging station with the $M / M / c / N$ model}

The mathematical method described in Section 2. can be used to model EV charging at charging stations. In this section we are going to present the mathematical method of modelling EV charging through numerical examples.

The modelling uses the $\mathrm{M} / \mathrm{M} / \mathrm{c} / \mathrm{N}$ model [7], [9], where the letters mean the following:

- the first M (Markov): Markovian (exponential) interarrival time distribution

- the second M (Markov): Markovian (exponential) service time distribution

- $\quad$ : : the number of servers (here the number of charging sockets)

- $\quad \mathrm{N}$ : the system capacity (here the number of cars that can be parked at the station)

Let us denote the intensity of the arrival of cars with $\lambda$ and the intensity of serving the requests (so to charge a car) with $\mu$. The flow diagram of the $\mathrm{M} / \mathrm{M} / \mathrm{c} / \mathrm{N}$ model is then the following:
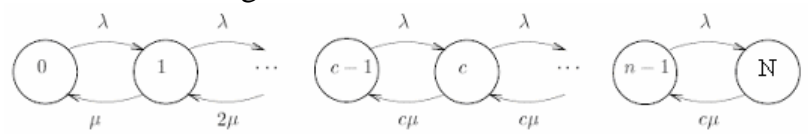

Fig. 1. Flow diagram of the $M / M / c / N$ model

Now we can construct the transition probability matrix $Q$.

To obtain the stationary distributions we have to solve the following set of equations: $\underline{\underline{Q}} \cdot \underline{\pi}^{T}=\underline{0}^{T}$, where $\underline{\pi}$ is the row vector that contains the stationary distributions.

0 By solving this set of equations and denoting the occupation rate with $\rho=\frac{\lambda}{c \mu}$ we obtain the $n^{\text {th }}$ stationary distribution: $\pi_{n}=\pi_{0} \frac{\lambda^{n}}{n ! \cdot \mu^{n}}=\frac{(c \rho)^{n}}{n !} \pi_{0}$ and after we have reached the system capacity $c$, we obtain 


$$
\pi_{c+n}=\rho^{n} \pi_{c}=\rho^{n} \cdot \frac{(c \rho)^{c}}{c !} \pi_{0},
$$

$n=0,1,2, \ldots, c+n=N$.

To solve these equations we consider $\sum_{k=0}^{\infty} \pi_{k}=1$, so we can obtain the $\pi_{0}$ stationary distribution:

$$
\pi_{0}=\frac{1}{\sum_{i=0}^{c} \frac{1}{i !} \cdot\left(\frac{\lambda}{\mu}\right)^{i}+\sum_{j=c+1}^{N} \frac{1}{c^{j-c}} \cdot \frac{1}{c !} \cdot\left(\frac{\lambda}{\mu}\right)^{j}}
$$

Using this formula we can also obtain the mean queue lenght:

$$
E\left(L_{q}\right)=\sum_{k=c}^{N}(k-c) \cdot \pi_{k},
$$

where $\pi_{k}$ is the the $k^{\text {th }}$ stationary distribution. After substituting the proper values and simplification of the equation we obtain

$$
E\left(L_{q}\right)=\frac{\pi_{0} \cdot \rho \cdot(c \rho)^{c}}{c ! \cdot(1-\rho)^{2}} \cdot\left[1-\rho^{N-c}-(N-c) \cdot \rho^{N-c} \cdot(1-\rho)\right]
$$

as the mean queue length and by Little's law we also get a formula for mean waiting time:

$$
E\left(W_{q}\right)=\frac{E\left(L_{q}\right)}{\lambda\left(1-\pi_{N}\right)}
$$

as mean waiting time [1], [2], [3], [4], [5], [6].

\section{Numerical results obtained from the proposed model}

The obtained equations allow us to make investigations by several different boundary conditions in how the changing of parameters affect the effectiveness of the service (eg. battery charging). This effectiveness is characterized by mean queue length and mean waiting time, so we can easily use our equations. We have implemented these equations in Excel Visual Basic and conducted several computations. We have used [7] and [8] as basics to construct these examples.

First, we have to set the parameters:

1. The first example models a smaller charging station where fast charging is possible. We analyze this kind of charging station in details because we can suspect that it is more vulnerable to the changing of parameters. This kind of station is a good model for stations along a motorway, where people do not want to wait long. The defined parameters are the following:

- $\lambda=1 / 3[1 / \mathrm{min}]$ : arrival intensity

- $\mu=1 / 50[1 / \mathrm{min}]$ : service intensity

- $\quad c=20$ number of charging sockets

- $\mathrm{N}=50$ number of parking slots at the station (including sockets)

2. The second example models a larger charging station where only slow charging is allowed. This can be the model of a charging station in a supermarket, where people would spend more than an hour. This charging station is characterised by the following parameters:
- $\lambda=1 / 3[1 / \mathrm{min}]:$ arrival inenstiy

- $\mu=1 / 240[1 / \mathrm{min}]$ : service intensity

- $\quad c=100$ number of charging sockets

- $\mathrm{N}=150$ number of parking slots at the station (including sockets)

During the calculations we keep some of these parameters constant, but others we will vary and investigate how this change affects the system parameters (mean queue length and mean waiting time).

We investigate worst case scenarios which means that we consider batteries to be fully depleted. Of course this is not the case in reality, but modelling the state of charge of batteries would be too complex and probably would be an understatement.

\subsection{Probability of not serving a request}

We cannot serve a request, so we have to refuse it to enter the queue if the system is full, so if there is no free capacity. This means that the station has no free parking space, so $N-n=0$ which means $n=N$. All we need to do then to obtain the probability that we do not serve an incoming request is to calculate the stationary distribution $\pi_{N}$ :

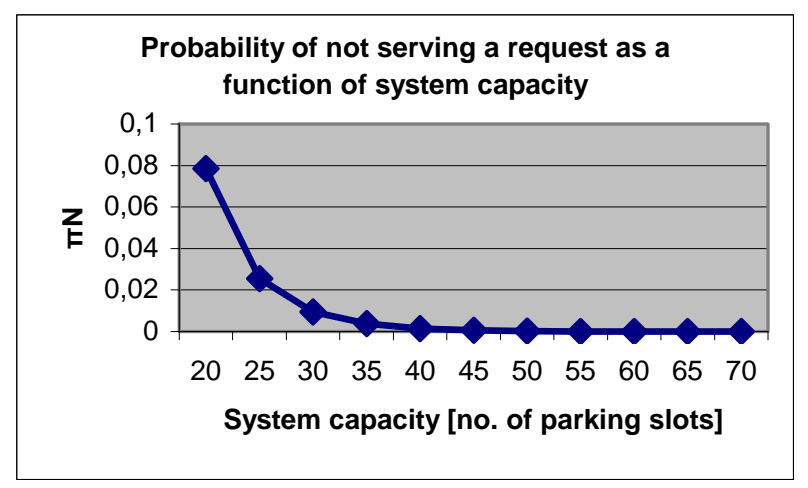

Fig. 2. Probability of not serving an arriving car as a function of system capacity (smaller station)

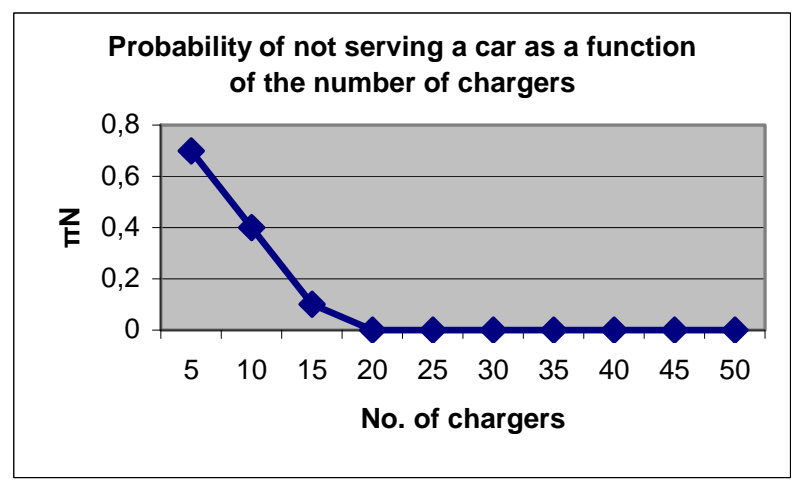

Fig. 3. Probability of not serving a car as a function of charging slots (smaller station)

The figures conclude that by increasing the number of servers and system capacity we can serve an incoming request safer. We can also observe that this probability reaches $O$ after a certain value of charging slots (in fact, due to the eqations it never really reaches 0 , but gets very-very close to it). This means that we should not have more charging slots than this determined value because we could not achieve anything with them. 


\subsection{Mean queue lenght}

It is usually not an easy task to find the distribution functions of the system parameters so we only find their mean values [5].

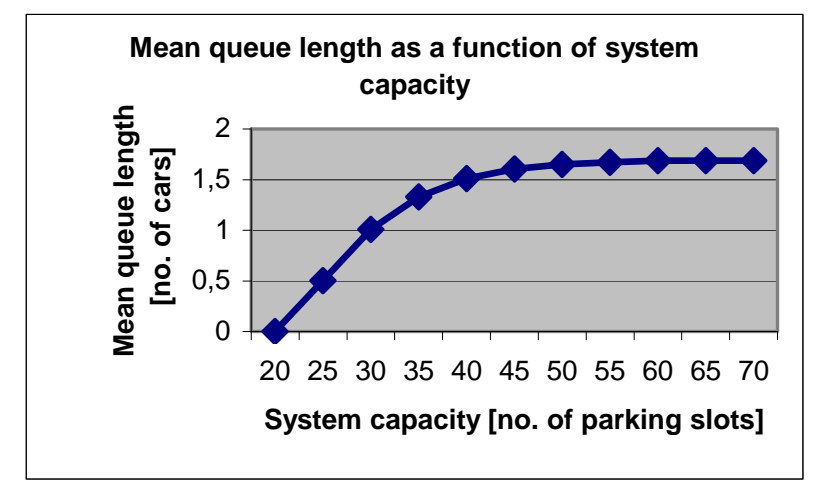

Fig. 4. Mean queue length as a function of the system capacity (smaller station)

Fig. 4. illustrates the mean queue lenght as a function of system capacity. When we increase the system capacity, the length of the queue would increase only slowly, and then becomes constant. We can state that the system capacity does not affect queues seriously.

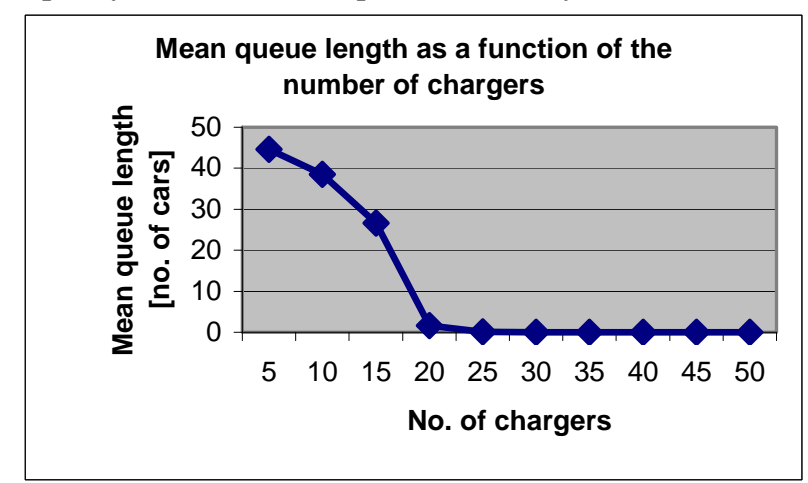

Fig. 5. Mean queue lenght as a function of charging slots (smaller station)

Fig. 5. represents the mean queue lenght as a function of the charging slots. When there are too few charging slots the requests cannot be served, so long queues evolve. By increasing the number of charging slots the queue lenght decreases and eventually there would be no queue if the number of charging slots is set properly.

Let us now investigate how the time needed to charge a battery affects the queue lenght:

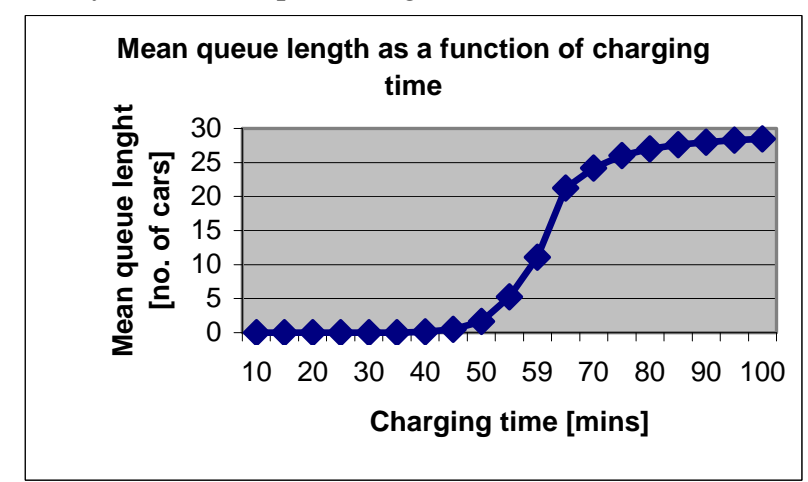

Fig. 6. Mean queue lenght as a function of charging time (smaller station)
We can state that the charging time has a greater effect on system performance than the parameters we have investigated so far. We can see on Fig. 6. that until a certain value of charging time there is practically no queue, but this queue evolves very fast as we increase the charging time. This fact concludes that the system is very sensitive to battery charging times and if we would like to design a charging station first of all we have to take this parameter into account.

\subsection{Mean waiting time}

Mean waiting time can be calculated from the mean queue length by using Little's law. We obtain the following results:

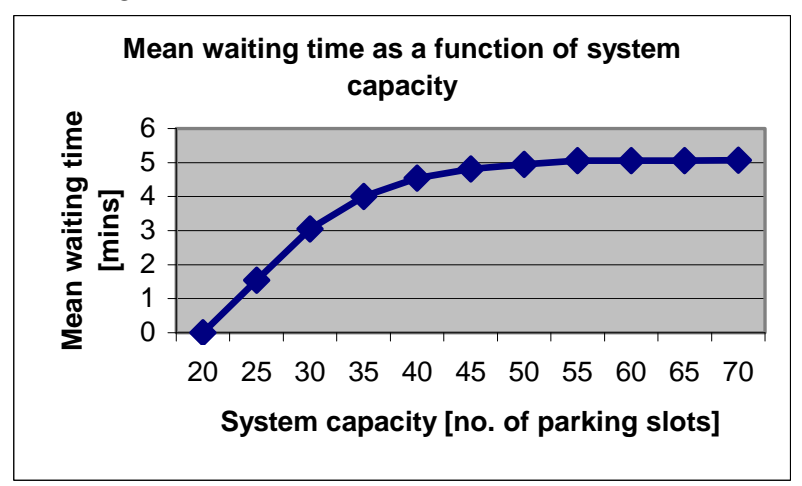

Fig. 7. Mean waiting time as a function of system capacity (smaller station)

We can see that no matter how many parking slots are there in the charging station we do not have to wait very long. We have to mention that this waiting time contains only the waiting time that we have to wait when there is no free charging slot. The time that is required to charge the battery is counted out of this value!

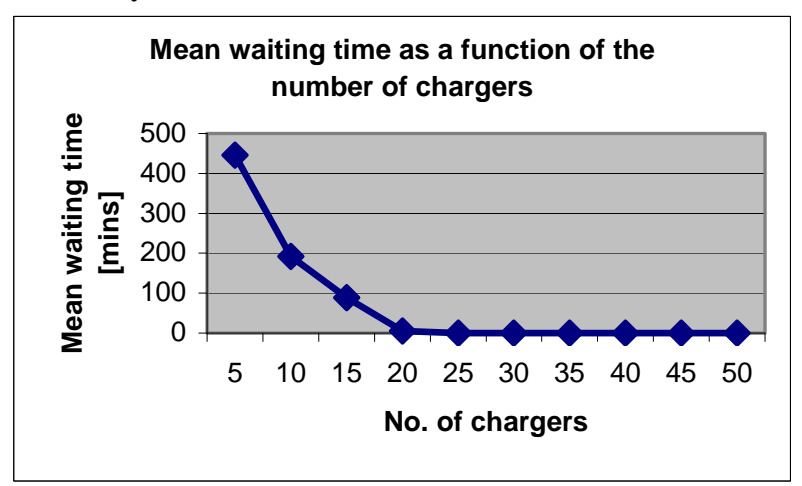

Fig. 8. Mean waiting time as a function of charging sockets (smaller station)

On Fig. 8. we can see that how the number of charging sockets affect the waiting time. If we have too few sockets, cars would have to wait for an unacceptably long time.

Finally we investigate the effect of battery charging time on mean waiting time: 


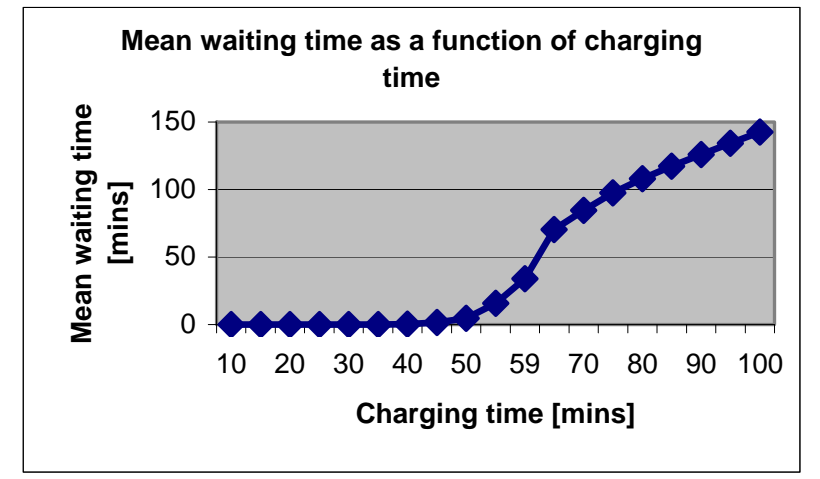

Fig. 9. Mean waiting time as a function of battery charging time (smaller station)

This result is very similar to the one we have seen on Fig. 6.: battery charging time has a serious effect on system performance.

\subsection{Rejection of arriving cars}

By multiplying the arrival intensity with the probability of not serving a car $\left(\lambda \cdot \pi_{N}\right)$ we can obtain the number of rejected cars per hour. We have seen that the parameter that affects system performance the most is charging time, so we present here the diagram that shows this function:

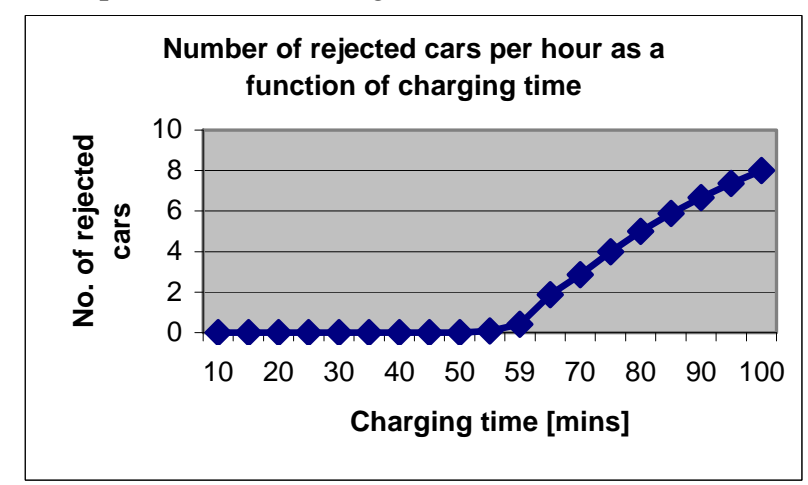

Fig. 10. Number of rejected cars as a function of charging time (smaller station)

This diagram does not carry further information but helps in understanding the importance of investigations in this topic. If we cannot charge the cars within a certain time interval the whole concept of the charging stations is becoming questionable. Fig. 10 reveals that even the owner of the charging station can have economical disadvantage: the rejected cars are lost customers.

\subsection{Investigating the bigger charging station}

We have conducted several computations regarding the smaller charging station, but we present here only the functions of battery charging time for the bigger station as we have seen by the calculations of the smaller station that this parameter is the most critical.

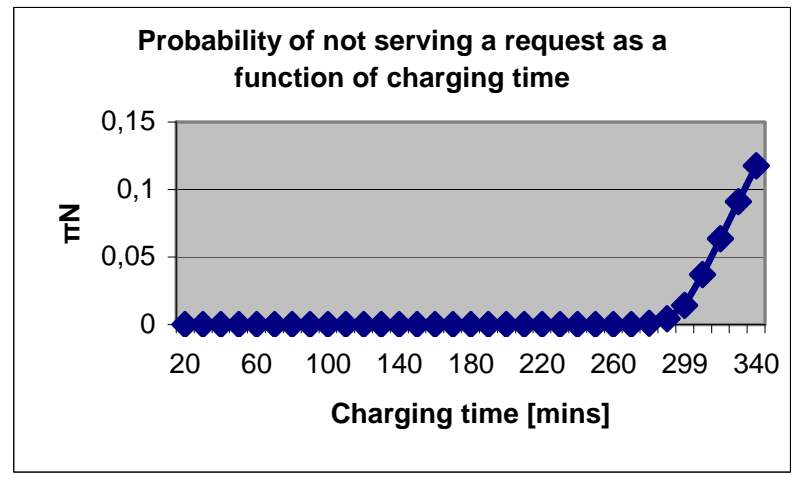

Fig. 11. Probability of not serving a car as a function of battery charging time (bigger station)

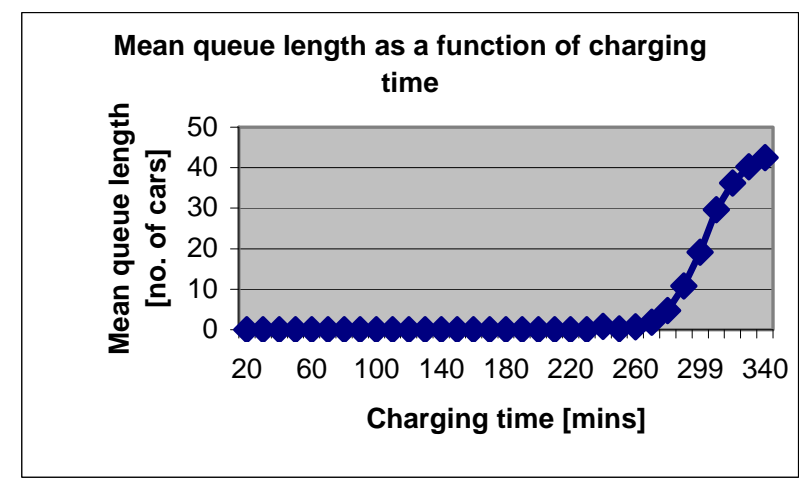

Fig. 12. Mean queue length as a function of charging time (bigger station)

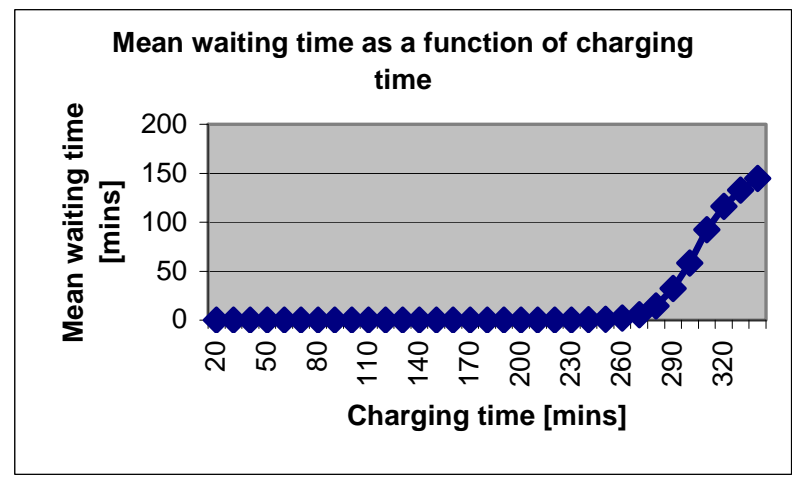

Fig. 13. Mean waiting time as a function of charging time (bigger station)

We obtained the same results as with the smaller station. It is obvious though that at a bigger station with slow charging one has to wait a lot just to get their cars charged. The not too short time that the charging of the battery requires is added to it.

\section{Add-in features: balking and reneging}

The proposed model still lacks some parameters that characterize natural behaviour of customers: these are balking and reneging:

- If we are to enrol a long queue, we often reconsider our decision and leave the queue and would come back later or would go somewhere else. This behaviour is modelled by balking.

- Reneging models the impatience of customers when they are already in the queue but cannot wait any longer and quit. 
It is obvious though that these phenomena are not only affected by customer behaviour. The state of charge (SOC) of the batteries are dominant in deciding whether to enrol a queue or not.

So when determining the balking and reneging parameters we have to take battery SOC into account as well.

1. Balking can be modelled with a parameter $b_{i}$ which modifies arrival intensity:

$$
\lambda_{n}=\left\{\begin{array}{cc}
\lambda, \text { until } & n<c \\
b_{n-c} \cdot \lambda, \text { when } & n \geq c
\end{array},\right.
$$

where $b_{n-c}$ is the balking parameter.

The flow diagram is then:
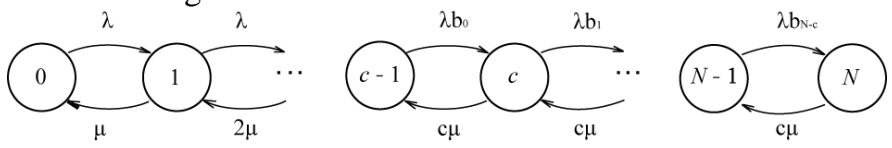

Fig. 14. Flow diagram of $M / M / c / N$ model with balking

We can calculate the desired system parameters like we did in the case without balking and we obtain

$$
E\left(L_{q}\right)=\sum_{j=0}^{N-c} j \cdot \pi_{0} \cdot \prod_{i=0}^{j} b_{i} \cdot \frac{1}{c^{j}} \cdot \frac{1}{c !} \cdot\left(\frac{\lambda}{\mu}\right)^{c+j}
$$

which we cannot express in a closed form.

2. We can model reneging with balking, so we use the previously defined $b_{i}$ balking parameter and we also introduce a $v_{i}$ reneging parameter which modifies the serving intensity. The flow diagram is then:
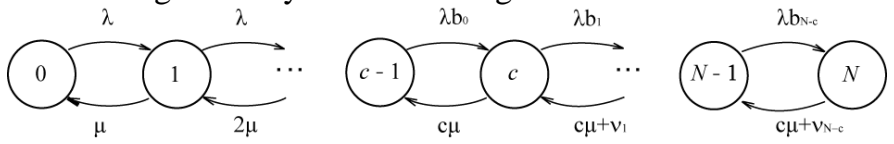

Fig. 15. Flow diagram of $M / M / c / N$ model with balking and reneging

We can calculate the system parameters again like we did before but we cannot express it in a closed form. To solve the cases with balking and reneging we have to use iterative solution methods.

We did not take these effects into account as they would make modelling more complex yet they don't affect the results seriously.

\section{Conclusions}

In this paper we have modelled the electric car charging stations using mathematical models. Investigations aimed to determine how system parameters (queue length, waiting time) depend on various designing parameters. We have conducted computations regarding two different types of charging stations: a smaller one with the possibility of fast charging and a bigger one where slow charging is also an option.

We can conclude our results as follows:

- The station's parameters (number of charging slots, parking space) does not affect seriously the system parameters. It is necessary to implement enough chargers or else customers will have to wait very long.
- Charging time has a serious effect on system parameters. The computation presented in this paper aimed to establish a method to investigate this effect.

- For bigger stations that can be built for example in a supermarket, charging time becomes important only at extremely long charging times. This is good for the system design as people spend more than one hour in a supermarket so we can implement slow charging there.

- However for smaller stations battery charging time is a more serious issue as long waiting times are unacceptable for customers. Considering even fast charging we can conclude that with the accessible batteries of today it would take too long to charge them at smaller stations and customers would have to wait even too long to be served. The smaller the station is, the faster we must charge the batteries. So we can state that these smaller stations are not yet ready for implementation: we have to wait until we can charge the batteries faster than we can now.

\section{Acknowledgement}

Authors would like to acknowledge the valuable contribution received from Mr. Imre Orlay, technology expert of DSO ÉMÁSZ

This work is connected to the scientific program of the "Development of quality-oriented and harmonized $\mathrm{R}+\mathrm{D}+\mathrm{I}$ strategy and functional model at BME" project. This project is supported by the New Széchenyi Plan (Project ID: TÁMOP-4.2.1/B-09/1/KMR-2010-0002).

\section{References}

[1] Dr. Sztrik János - Raktározási és kiszolgálási problémák matematikai modellezése (Mathematical modelling of storing and serving problems) (in Hungarian)

http://irh.inf.unideb.hu/user/jsztrik/education/14/opkut.pdf

[2] http://www.renyi.hu/ major/debrecen/markov3.pdf (In Hungarian)

[3] Felsőbb matematika villamosmérnököknek (Advanced mathematics for electric engineers)_www.math.bme.hu/ szbalazs/vill

[4] Fenyő István, Frey Tamás - Matematika villamosmérnököknek I. (Mathematics for electric engineers I.)

Müszaki Könyvkiadó, Budapest, 1964,

VII. fejezet: Valószínüségszámítás (in Hungarian)

[5] Dr. Sztrik János - A sorbanállási elmélet alapjai (Basics of queueing theory) (in Hungarian)

http://irh.inf.unideb.hu/user/jsztrik/education/17/SOR_Main.pdf

[6] Csaba Farkas, Kristóf István Szabó, László Prikler - Impact assessment of electric vehicle charging on a LV distribution system 3rd International Youth Conference on Energetics, 7-9 June 2011, Leiria, Portugal

[7] Honma Yudai, Kurita Osamu - A safety stock problem in battery switch stations for electric vehicles, The Eighth International Symposium on Operations Research and Its Applications (ISORA'09), Zhangjiajie, China, September 20-22, 2009, pp. 332-339

[8] Rodrigo Garcia-Valle, John C. Vlachogiannis - Electric vehicle demand model for load-flow studies, Electric Power Components and Systems, vol 37., 2009., pp. 577-582

[9] J.P.C. Blanc-Queueing models: Analytical and numerical methods Course 35M2C8, Department of Econometrics and Operations Research, Tilburg University, http://lyrawww.uvt.nl/ blanc/qmblanc.pdf 